\title{
A BAND WITHOUT WALLS AT THE END OF THE WORLD: The Green Mist, Next Stop Antarctica and the Tasmanian geographic imaginary
}

\section{Transforming Cultures eJournal, \\ Vol. 4 No 1 April 2009 \\ http://epress.lib.uts.edu.au/journals/TfC}

\section{Keryn Stewart and Helen Hopcroft ${ }^{1}$}

\begin{abstract}
The Green Mist is a floating international blues entity which evolved in the deep south of Tasmania. Featuring former members of the Violent Femmes and Beasts of Bourbon, the Mist's first album Next Stop Antarctica represents a vivid evocation of the peculiar strangeness of the island's atmosphere, history and environment. Musician Julien Poulson's father Bruce was a historian who lived in a derelict organic garlic farm in the small town of Southport; an area that is often bitterly cold, perpetually gloomy, bleak yet strangely beautiful. Bruce was one of the people who discovered the remains of a garden built in 1792 by French explorers in Recherche Bay, and this discovery was later used to help protect the site from logging. While his dad was dying of cancer, Julien helped him put together his final book about Recherche Bay's history and later many of these old stories formed the basis of album tracks. Using The Green Mist as a case study, this paper will explore the links between physical place of production and creation; the use of both individual memory and historical narratives in song writing; and the extent to which these factors form part of a conscious or deliberate strategy.
\end{abstract}

\section{A Tasmanian Imaginary}

Dangling precariously from the landmass of southern Australia, the island state of Tasmania has always held a fascination for those who deal in matters of the imagination. It is a place of extremities, the southernmost outpost of the southernmost continent, whipped by icy winds from the pole; it is also a place of isolation, the final banishing point for the convicts whose bloody punishment marks the island's history.

\footnotetext{
${ }^{1}$ Keryn Stewart is Senior Web Information Copywriter at the University of Newcastle. Helen Hopcroft teaches at Newcastle University, Australia.
} 
Maria Tumarkin (2001: 202) argues that Tasmania functions as the "geographic unconscious" of Australia, a place beyond the edge of the known world on which anxieties and fantasies are displaced and contained. Writer Martin Flanagan (1999: 4) also places the imagined at the heart of Tasmania's geography: Tasmania, he says, "is more than a place - it's an idea, a potent one, since it presents certain fundamentally Australian themes in their most concentrated and focused form".

There is a story, possibly apocryphal, of the colonial history of Tasmania that captures this sense that geography on the island holds more potency as an imaginative idea rather than reality. The story relates the tale of an escaping Irish convict fleeing into the bush, guided only by his "compass": a piece of wood with an arrow drawn on it next to the word north. This image of the needleless compass is specifically referenced in the artwork for the album sleeve of Next Stop Antarctica, a 2007 album by Tasmanianbased musical collective The Green Mist. It encodes not only the sense of strangeness and disorientation felt in this small island at the bottom of the world, but also the ways in which the imagined dimension of place comes to have potent power in our authoring of individual spaces.

In recent years, there has been an explosion of critical interest in the roles that different dimensions of the spatial play in the spectrum of social, cultural and historical experience (eg Soja 1996, Massey 1999, Appadurai 1990). Since this turn to what Keith and Pile (1993: 9) term the "spatial vogue", much time and critical energy has been expended in attempting to untangle the specific relations between space and place; however, as McAuley (2006:16) notes, there is no theoretical consensus on this relationship, with place "sometimes conceptualised in opposition to space, sometimes coupled with it in a dialectical relationship".

In the context of popular music studies, the search for social and cultural meanings in popular music has been greatly enriched by this shift towards recognising the primacy of place, not only in the representation of local environments but also in their production. Bennett (2004: 3) summarises the significance of music in this process of the production of place:

Music...plays a significant part in the way that individuals author space, musical texts being creatively combined with local knowledges and sensibilities in ways 
that tell particular stories about the local, and impose collectively defined meanings and significance on space. At the same time, though, it is important to note that such authorings of space produce not one, but a series of competing local narratives.

In this paper, we seek to explore the authoring of space undertaken in The Green Mist's Next Stop Antarctica, concentrating on the ways in which its collection of tracks tell 'stories' about the specific place of Tasmania while also engaging with the narratives inscribed on and produced from that place. We argue that in the Tasmanian context, perhaps more than in mainland Australia, the process of musical production is intimately bound up with local resonances of history that express themselves via "place memory" (Casey 1987) and specific narrative modes such as Tasmanian gothic.

The paper also concentrates on ways in which influences external to the local environment are used to explicate the geographical imaginary of particular places. By taking musical styles and genres with embedded geographical and spatial meaning, such as blues and the road song, and placing them in a Tasmanian context, The Green Mist teases out a sounding of place that not only draws imaginative equivalence between seemingly disparate environments but also locally adapts their meanings. This is not to argue for a specific "Tasmanian" or "Hobart" sound in the sense of say, the "Motown Sound", but rather to acknowledge the ways in which sounds from 'there' can be used to produce the idea of 'here'.

Finally, we look briefly at the ways in which the virtualisation of place through the Internet and electronic media have affected the concept of a specific Tasmanian place identity, and on how technologies of production and distribution influence local and global imaginings. Throughout all of these sections, we rely not only on the musical texts themselves but also on interviews conducted with band members Julien Poulson and Brian Ritchie, and on information sourced from the band's MySpace web page.

\section{Next Stop Antarctica: the album}

Next Stop Antarctica is the first album by The Green Mist, a musical collective headed by native Tasmanian Julien Poulson and comprised of a number of musicians from both on and off the island, including members of The Beasts of Bourbon and The Violent Femmes. Conceived and written in the far south of Tasmania, the album draws on 
historical narratives, mythology and folklore to evoke a rich sense of the isolation, geographical extremity and dark historical resonances of the local landscape. Stylistically, the album is varied, with tracks veering from brooding instrumentals to dirty down-home blues and airy folk-inflected pop.

The album is less of a collection of songs than a soundscape, a three dimensional evocation of the circumstances of the album's creation and a record of a peculiar place at the bottom of the world. Like a series of black and white photographs being thrown onto a table, the music evokes images of road trips, isolated townships, freezing share houses, grey skies, nuclear winter sex and wild nights spent in pursuit of Hobart's unreliable supply of illegal drugs.

The title of the album, Next Stop Antarctica, reflects both the geographical isolation of Tasmania and its psychological disjunction from the rest of Australia. It figures Tasmania as the final stopping point before the frozen wastes of the South Pole, an outpost remote even from the already remote continent of Australia. The album title also reinforces Jim Davidson's contention that "Tasmania has always seemed 'different' from the mainland' (1989: 89); in contrast with the sunburnt desert landscapes that are the dominant representation of the Australian geographical environment, Tasmania has a landscape of dripping greenness and a climate of harsh extremity. Bitterly cold and raging winds traverse the globe before slamming into the island's west coast, and gales race up across Antarctic waters and hurl themselves against the south. In some parts of the island, trees grow pretty much parallel to the earth. This sense of remoteness and disjunction resonates through the soundscape of the album, as we shall discuss further below.

In its production as well as its poetics, Next Stop Antarctica engages with complex questions of place, stretching the limits of what constitutes "Tasmanian" music. While the album was conceived, written and partly recorded in Southport and Hobart, the actual production and final recording of the album was undertaken in Melbourne, and the album was eventually released by a Spanish label specialising in "underground" Australian music. Julien Poulson has said that the band was conceived as a floating international entity, a multimedia rock'n'roll group with an eclectic and fluid membership from around the world: in his words, "a band without walls". 


\section{Navigating the soundscape: "Black Louie's Ambergris", landscape and historical reimaginings}

The genesis of this article was the seemingly simplistic observation that the first instrumental track on Next Stop Antarctica, "Black Louie's Ambergris", sounded like a particular landscape: specifically, the landscape of the far southern coast of Tasmania. With its sombre tones, dense instrumentation and eerie, howling flute counterpoint, the track echoes the sounds and atmospheres of the extreme south, the "last stand of Earth before the pole" (Conrad 1988:47) where bitter gales race up across Antarctic waters and hurl themselves against fractured cliffs. The landscape of this ruptured shore reveals itself in the ebbs and flows of the music, the desolate skirl of the flute and the barest hint of a shanty in the weaving melody.

Yet purely sonic indices are not reliable as stable markers of place (as opposed to landscape), as their interpretation is highly subjective. If you were to listen to the track in isolation, there is no specific sound or note in "Black Louie's Ambergris" that could identify it to a casual listener as Tasmanian, much less an evocation of the geographically specific landscape of the far southern coast. The track is wholly instrumental, allowing no lyrical clues to its geographical locale, and, unlike some forms of "world" music, there are no culturally specific instruments that might provide a geographic pointer. Indeed, the uncanny howling sounds that mimic the blustering bleakness of the ocean gales are actually produced by a shakuhachi, a traditional Japanese bamboo flute, which would seem to muddy the geographical waters even further. It is one thing to say that the track sounds like the sea, but quite another to say which sea, to locate the track in a specific geographical context.

How, then, does a musical evocation of landscape, however picturesque, change into a representation of place, with all the geographical, cultural and historical specificity inherent in the concept? Ball (2003: 117) locates the crucial shift as essentially linguistic, positing that specific geographical place naming is key; for him, "naming symbolizes a sense of history and socialization of the land; it transforms Landscape into Place". Jim Davidson (1989: 316), writing on Tasmania, concurs; he quotes expatriate Tasmanian Peter Conrad's formulation that "writing instils a spirit in place since it 'subdues things by describing them"'. Certainly, in naming the album Next Stop Antarctica, The Green Mist takes a potent step toward locating the tracks in a Tasmanian context. Yet naming is only one means by which the complex relationship 
between space and place can be explicated. A fuller articulation can only be gleaned from an understanding of the circumstances of the album's creation and production; that is, by the "recognition that musical processes take place within a specific space and place, and are shaped both by specific musical practices and by the pressures and dynamics of political and economic circumstances" (Whitely 2004: 1)

That this track was conceived and written by Julien Poulson on a trip home to Tasmania, and that its contours were defined as he helped his historian father finish his final book about the history of Recherche Bay in Tasmania's far south, thus becomes not only biographically interesting, but crucial to the imagining of place in the album.

In face, the whole album was written while Julien was sorting through his father's often chaotic collection of unedited pictures and materials; the process of putting his father's book of history together was to have a profound influence on the music, with text and images often providing the narrative backbone for tracks. Commenting on the process of conceiving and writing the album, Julien notes that "[sorting through the papers] definitely affected the way I put the music together...all that reference material was a huge influence". This influence is multi-layered; while specific narratives from these historical sources are obviously referenced in the album, other elements of the material past edge their way into the work more subtly, engaging with the stylistic and geographical tropes already present in the music.

One such element is the negotiation of Tasmania's peculiar history, and the ways in which this can be represented. The published form of Bruce Poulson's book, Recherche Bay: A Short History, takes a traditional chronological approach to the history of Recherche Bay, each chapter tracing the individual histories of its inhabitants from the first indigenous Tasmanians onwards. Moving briskly through its motley cast of French maritime explorers, bushrangers, boatbuilders, mutineers, whalers and modern-day environmentalists, the book seems to situate the history of the far south as rich and varied, but also contained and explicable. The brutal events of colonial occupation and convict transportation are juxtaposed with more domestic narratives of settlement and cultivation, all narrated factually in fluent, objective prose. 
Next Stop Antarctica absorbs and refracts this historical material; instead of directly voicing the stories and histories of the individuals whose experiences made up the place of Recherche Bay, the tracks use instrumental interpretations to convey the atmospheric resonances of these narratives. This approach was a deliberate one; indeed, lyrics inspired by Bruce's research were jettisoned during the recording process. The track 'Dirty Big Low' originally had lyrics about a murderer who was shot by police after fleeing to Northern Australia; by the time the band got to the recording studio it had become a purely instrumental piece.

Similarly, the instrumental "Black Louie's Ambergris" is based on an old Recherche Bay story told to Julien by his father, of two men, Black Louis and Black Harry, who made a fortune by finding a huge supply of ambergris in a whale carcass. At the time ambergris (usually hundreds of squid beaks swallowed but not digested by a whale) was used as an ingredient in expensive perfumes, incense and oils. One man later drank himself to death, the other prospered and the remains of his house can still be seen in Hythe, near the small town of Southport. In keeping the track an instrumental one, The Green Mist thus elects not to speak with the voices of the past, but rather to subsume those voices into a geographical soundscape that draws on their historical resonances to construct a specific conception of place.

These historical engagements highlight our contention that the apprehension of place must be sought from more than the sounds themselves; these sounds must be set against a context not only of the other sounds that constitute a place, but also against the existing narratives and cultural representations that make up its geographical and social imaginary. With this in mind, we turn to one of these ways of making meaning out of place: the Tasmanian gothic.

\section{Sounding out Tasmanian gothic}

Space defines landscape, where space combined with memory defines place (Lippard 1997: 97)

One of the most potent ways in which the place of Tasmania has been apprehended is through the mode of Tasmanian gothic, which takes as its central concern a focus on the 
island's brutal history, its remoteness and its cultural insularity (Ball 2003: 117). By working through some of the issues of cultural and place identity encoded in Tasmanian gothic and refiguring them musically, Next Stop Antarctica uses this form both to evoke a sense of place and also to produce it.

Place and spatial concerns resonate through the Tasmanian Gothic sensibility; the landscape is seen as an active element in the gothic narrative, even a quasi-sentient force animated with menace. Tasmania's wild landscapes and grimly picturesque ruins, with their links to the violent and bloody convict past of the island, provide fertile ground for gothic imaginings; artists, writers and critics have long used the island as an imaginative site to play out these concerns. The gothic is also characterised by disjunctions and ruptures in time (Davidson 1989: 318); in this mode, the past is perilously close to the surface of the present, always threatening to rupture its seeming stability.

Listening to Next Stop Antarctica, with its evocations of desolate landscapes, roadside graves and lonely highways, the sense of the gothic is strong; it feels like all of Tasmania's strange history, isolation and spiritual resonance is burning up through the surface of the music. The "graves, flowers and notes scattered all along the way" in the track "Roadside Graves" refer at first glance to the common phenomenon of markers placed at the scene of road accidents, but also evoke the unmarked graves of massacred indigenous Tasmanians, or the similarly shallow burials of nameless convicts fleeing into the swallowing bush. In describing how the evocation of place was handled in Next Stop Antarctica, Julien Poulson's formulation focuses on this sense of the gothic:

I believe the history of violence in Tasmania has left an indelible stain. I also feel it is a place of brooding violence in its natural context, wild storms, battered coasts, stunted trees of the central plateau.

He also refers to the way that the atmospherics of the album are produced in terms that strikingly mirror the gothic process: "like something seeping out and finding its own space within some other matter...like rising damp in an old house" (quoted in Shannon 2008). This sense of seepage, of the inability of place to successfully contain the events and histories it holds, is closely linked with Casey's concept of place memory. 
The epigraph to this section quotes Lucy Lippard's contention that memory is the most crucial element of distinction between landscape and place; in Tasmanian gothic, however, the repository of memory is transferred from the inhabitants of the landscape to the landscape itself. As Gay McAuley (2006: 170) describes,

Certain places seem to function dynamically to "hold" the memories of events that occurred there, even though the events may be denied...even though it is the community's desire to move on.

In the gothic, though, places do not only hold the memory of traumatic events; they extrude those memories into the present, causing "hauntings" and echoes. To this day, Tasmania is prone to the occasional horrific crime, with a murder rate that for many years was higher, on a per capita basis, than anywhere else in Australia. A man cut off his hand after killing his children; a woman was skilfully dismembered in the family bathtub; a mass killer hunted people at a popular tourist site. When these terrible crimes occur you feel that something from the past has suddenly shot up through the surface of the present, wreaked havoc and then submerged back into the earth.

This fracturing of time, as we have seen, is a key element of the gothic; Maria Tumarkin (2001), in her powerful examination of traumascapes, explicates the way that the "traumatic repetitions" attributed to landscapes of violence and tragedy result in nonlinear time structures being attached to those places, as individuals and communities seek to come to terms with the trauma invested in them.

The sense of place created by Tasmanian gothic, then, is one that intercesses the past with the present; that evokes a fragmented, non-linear view of time; and that privileges atmospherics and "hauntings". Next Stop Antarctica weaves all of these concerns together to create a particular sonic "feel", what Ian Maxwell (2006: 49) terms an "imaginal" rendering of place. The historical presences (and absences) evoked in the instrumental tracks mingle with the runaways, alcos and drifters of the contemporary songs. The tracks flicker between moods and musical styles with a rapidity that is both mercurial and menacing, breaking up the linear progression of the album into shifting atmospheric zones. Reinforced by the grainy black-and-white historical photographs of stormy seas and hard-faced southern sailors that line the record sleeve of the album, the entire thrust of the album is towards a poetics of haunting, of history making its presence felt in a contemporary creative work. 
It is interesting to note that Tasmania as a gothic imaginary has been largely created through forms other than popular music. Jim Davidson (1989) has traced out the contours of Tasmanian gothic in Australian literary and cinematic representations of the island, while Edward Colless has undertaken similar work in the visual arts. Popular musical forms have not, in general, been subject to the same analysis; although, as Ball (2003: 115) has shown, the work of Australian composer Peter Sculthorpe engages with the tensions between gothic and pastoral aesthetics in the Tasmanian landscape, this musical representation takes place in the sphere of "classical" rather than popular music.

Tasmanian gothic, unlike other gothic modes, is primarily a non-urban mode of representation, which is perhaps one reason that it has not figured prominently in the primarily urban spaces of the production of popular music in Australia. Yet music, perhaps more than other creative forms, offers a means of representing the gothic's ruptures and disjunctions of time and space through contemporary production techniques such as sampling, looping and layered tracks. Outside Australia, this potential has been explored to great effect, with the burgeoning electronic music subgenre of "hauntology" juxtaposing "found sounds" and sampled nostalgia with ghostly sonic echoes to both evoke and question an imagined lost world (Cole 2007). In the Australian context, Next Stop Antarctica surveys similar psychogeographical territory, while anchoring itself firmly within an established imaginary of Tasmanian gothic. At a time when gothic has been criticised as a deadening cultural appropriation of a living culture and people (Flanagan 4), Next Stop Antarctica takes back Tasmanian gothic as an enabling cultural mode for representing place.

\section{The Wild West (or the wilder South): drawing imaginative equivalences through musical style}

... if Next Stop Antarctica is any indication, Tasmania is strangely akin to the desert southwest of the United States: country blues, Mexican folk music, and atmospheric Hollywood soundtracks co-mingle freely across these ten tracks of largely acoustic indie rock. (Mason 2008)

Not all the songs on Next Stop Antarctica evoke the stark landscape and howling winds of the far Tasmanian South; rather, tracks such as "The Rumbler" and "City is Sinking" 
swagger to the stylings of another south altogether. These tracks incorporate blues, slide guitars and even Mariachi-style acoustic rhythms to shift the sonic landscape of the album to the American South (and West).

While, at first glance, the High Noon recklessness and southwestern twang of these tracks seems far removed from the chilly waters of Macquarie Harbour, these, too, reflect the odd lawlessness of Tasmania's history. Many years ago, Hobart was a major international port and the waterfront was infamous for its brawls, brothels and hard drinking; before that, the unruly revels of colonial times gave Hobart Town a deserved reputation for disorder. Even today, beneath its conservative and rather boring facade, Hobart remains something of a wild town; there's this feeling that the central tenets of the legal system have been applied but never really internalised.

The Wild West feel for Next Stop Antarctica is not unplanned; Julien Poulson, in the online press release for the project, describes the collective as:

A bunch of 'characters' like the cast of a Sergio Leone Western...y'know, gringos, bandidos, femme fatales and all...the good, bad and ugly of Australian rock'n'roll (Bang! 2007)

The same press release also characterises the band as musical "renegades" interpreting "blues and cowboy song traditions", locating the stylistic home of the album in the American badlands at the same time as it appropriates the outlaw characterisation associated with that place.

One way that this is achieved is through the recognition that these two dissimilar landscapes - the Wild West and the wilder south - both resonate most strongly as imagined places. These are each mediated through specific creative (though nonmusical) forms that prioritise particular aspects of their geographical and cultural imaginaries. For Tasmania as imagined place, the dominant cultural form is literature, and specifically the mode labelled Tasmanian gothic; for the Wild West, it is the cinema of spaghetti Westerns. Next Stop Antarctica uses this imaginative equivalence to map out a spatial politics that interrogates the effect of place on its Tasmanian narratives. The characterisation of the band members as "renegades" and "outlaws" acts as cultural shorthand for both an entrenched lawlessness analogous to Tasmania's wild colonial history and as a marker of the creative iconoclasm the band hopes to invoke in its 
music.

Styles and genres from other places can also have crucial effects on the development of a "local" sense of place. As Bennett (2002: 89) has noted, styles such as blues are tied up in their own dynamics around the production of place:

The marketing of canonized 'genres' such as Cajun, blues and 'world music' has served to create a series of romanticized myths surrounding particular regions of the world as listeners use these musical styles as a means of mapping out the relationship between social and geographical landscapes.

Extending Appadurai's formulation of "scapes", Bennett proposes that the places produced from the mapping of these musical relationships are best understood as "mythscapes"; that is, spaces which are "mythologized as in some way informing the essential spirit of a body of live and recorded music" (98). These spaces are linked to but separate from the physical cities and landscapes that they reference, existing in a cultural imaginary that is created and elaborated through electronic and other media. In referencing blues, country and Mariachi music, then, Next Stop Antarctica draws on the potent mythscapes associated with those styles to draw equivalent parallels about authenticity and the meaning of place.

The mythscapes associated with Mariachi music, swampy blues and twangy guitars all evoke particular regional imaginings; however, one specific spatial mode through which they are linked is through the trope of the "soundtrack". All of these genres have been figured as constituting the "soundtrack" of a particular region of the American South or West; their development runs parallel to the history of the regions, and they both voice and shape the geographic imaginary associated with them. Through invoking these heavily invested styles, Next Stop Antarctica signals its intention to aim for this kind of place-making role as well - to act as a "soundtrack" for Tasmania. Coincidentally, the album's creative genesis was as a film score for a proposed film set in Tasmania; the film never eventuated, but its soundtrack lives on.

Another genre with embedded spatial politics that are referenced and transformed in Next Stop Antarctica is the road song. Although not as potently regional as the genres discussed above, this type of song, as Leyshon, Matless \& Revill (1998: 22) note, emerged from a specific time and place: "the freedom and escape of the road song as a 
commercially popular genre is historically particular, driven by American youth...speeding in postwar affluence out of suburban confinement". The tracks "Roadside Graves" and "Roads and Cars" on Next Stop Antarctica, however, transfigure these traditional notions of escape and ease by placing them in the confined and historically complicated setting of Tasmania.

"Roads and Cars", with its refrain "I keep thinking about roads and cars", is actually a song about stasis; the narrator imagines movement and freedom, but always in the future tense, and always triggered by an action outside her own agency:

If you needed me, I'd come running to you/If you called for me, I'd drop everything/When you're bored of me, I would change something...

At the end of the song, she is still "thinking about roads and cars", still in a state of limbo. This sense of going nowhere - of circularity and claustrophobia - evokes the feelings of many creative Tasmanians who, like Julien Poulson and Peter Conrad, left the island as soon as they were able.

Similarly, the orientation of the road song is drawn off course by another track on the album, "Roadside Graves". As we have seen above, road songs evoke escape and the movement away from familiar places into the open space and freedom of the unknown; in "Roadside Graves", though, the drift is toward home, not away from it: the girl at its heart is "Just another soul travelling on the road back home". Home is figured as a place that has become unknowable, encrypted by the passage of time and history: "Never really knew what it meant to be there/And she never really knew what it meant to leave there". Places along the road attain a haunted quality that evokes Tasmanian gothic; they "flicker and fade in the rear view mirror". Finally, the girl of the song becomes a shade herself, like the presences of those who occupy the roadside graves: she appears "Like a ghost in the middle of the road". In Tasmania, the revenants of personal history become intertwined with the history of the place itself; the usual bonds of personal and familial history, what Peter Conrad refers to as "the past [that] waited here to take me prisoner" (1988: 9), are overlaid by the sense of Tasmania itself as a prison. 
The Green Mist's reconfiguring of these particular genres thus uses their embedded spatial imaginaries to tell specific Tasmanian "stories"; sounds from 'there' become a potent means of expressing the sounds of 'here'. The title of the album, Next Stop Antarctica, not only functions as a marker of geographical isolation and extremity, but also acts as a type of conceptual container for the tracks within; while other places may be evoked and referenced, the title sets the psychological coordinates of the album firmly within Tasmania's borders.

\section{Virtualising place: some final notes}

Thus far, this piece has concentrated primarily on the sonic and textual representation of place within the album Next Stop Antarctica. In this final section, we would like to shift focus slightly to consider how this sense of place is mediated by the circumstances of its distribution and reception. Though influenced by Appadurai's (1990) formulation of "scapes", especially the "mediascape" and "ethnoscape", this section seeks more to identify ways in which The Green Mist uses the virtual environment to escape the limitations of geographic isolation and to avoid identification with a particular localised "scene". The empirical focus of this section is on the band's MySpace page at $<$ http://www.myspace.com/themysteriousgreenmist/>.

When accessing the primary MySpace website, users are presented with a number of means through which particular artists or groups can be located; prominent among these are the options to search by genre or style, and to search by location.

These twin concerns of geographical place and musical style align closely with those explicated in the current critical environment around the analysis of "scenes", of which Bennett (2002: 90, italics ours) has provided a useful summary:

Existing work on music scenes tends to view such scenes either as organic extensions of particular localized communities (see, for example, Cohen, 1991; Shank, 1994) or as translocal phenomena which 'actualize a particular state of relations between various populations and social groups, as these coalesce around specific coalitions of musical style' (Straw, 1991:379; see also Lewis, 1992)."

Bennett goes on to argue for a shift in the critical understanding of music and place that acknowledges the "new constructions of [the] relationship" precipitated and enabled by 
electronic media such as the Internet, particularly around the construction of virtual, geographically dispersed fan communities (2002: 98).

In the case of The Green Mist, these scene-defining categories of place and style have been self-consciously destabilised, as expressed on the project's MySpace page. Although the style of the project has been variously described by reviews and in their own press as "country blues" (Mason 2008), "rock and roll” (Wilson 2008) and "folk" (Bang press release, no author specified, 2007), the project playfully defines its musical style as "Screamy, Religious, Classic". While this is a refreshing antidote to the finicky and often po-faced stylistic categorisations undertaken by many other MySpace bands, the patently inaccurate style markers also act as a barrier to Bennett's (2002) notion of virtual community as described above, stymieing fans who might be searching by genre, style or "sound".

In terms of place, too, The Green Mist once again puts forward a wilfully mysterious self-presentation. Fans searching for a specifically Tasmanian or Hobart-based group might emerge confused by The Green Mist's listing. Geographical identifiers, far from tying the project to a specific place, have been layered on top of each other in seeming contradiction; the project, though conceived and written in Tasmania, lists as its location "Phnomh Pehn, Hobart, Darwin, Antarctica".

At first glance, these markers of place appear antithetical. In psychological as well as geographical terms, Darwin is about as far away from Hobart as it is possible to get: the most northerly city in Australia, its mangoes, feral heat and proximity to the nations of Asia contrast sharply with the chill and isolation of Tasmania's capital. Interestingly, though, Darwin too is a geographic imaginary outside the Australian mainstream, its tropical fecundity and vibrant intermingling of cultures and ethnicities contrasting markedly with the parched desert and emptied outback of Australian self-imagining. This marginal geography aligns it with the other "extreme" representations of place in the location listing, not only Hobart but also Antarctica, the extension of the margin to the literal "end of the world".

The final geographical place name listed, Phnomh Penh, encodes a different kind of marginalisation: that of people culturally dispossessed and traumatised by the 
experience of war. Julien Poulson travelled recently to Cambodia on an Asialink residency to work with some of Phnom Penh's traditional musicians, many of whom suffered dreadfully under the Khmer Rouge. The Green Mist links these seemingly diverse geographical referents by bringing the concerns of the marginal to the centre of the project, and by tying this in to the self-consciously "international" flavour of the project.

The mobility of place association in the virtual environment is linked to the liberating effect of musical technologies; local sounds can now be recorded and produced easily and cheaply on computers, something almost unthinkable in the days of record company domination. As Poulson notes, this has reduced the need for the cycle of flight and reluctant return that has characterised Tasmanian cultural production:

Until recently you had to leave the State to do anything. There were limited opportunities beyond just playing covers for tourists.

Yet, paradoxically, this fluidity has also made it easier to leave; in a world constituted by the constantly shifting flow of information and people across and beyond borders (Appadurai 1990), the notion of a specific geographical identity has also become a mobile one. This portability, and the concurrent sense of its marketability to consumers of music from other places, is exemplified by Poulson's words below:

I definitely carry with me a sense of Tasmanian identity and this 'place' creeps into the work; it's also of interest to audiences and the people who have copies of The Green Mist material released here in Europe. It's really appealing to people on the far side of the world. They kind of discovered it on the internet and started emailing us, and now the Spanish ring up at 3 o'clock in the morning and go, 'Hola! Green Mist, we love!'

In some ways, the virtual constitution of the project is an attempt to harness the positive multidisciplinary nature of the existing arts community in Hobart, which by virtue of its small population and close geographical proximity results in a fertile creative environment where multimedia collaborations are considered normal, indeed inevitable, while taking the music to a global market. This movement to the virtual space is also a deliberate (and mostly successful) strategy by producers of music to confront and overcome the cultural limitations of these local "scenes". However, there are still challenges associated with producing and distributing music in remote environments: 
[M]ost of The Green Mist's finished recordings have been completed in Melbourne: I've still had to rely on working with experienced studios in big cities. While living in Tasmania, I've had freedom and time to create and prepare work, and new technology has made it possible to record and capture sounds anywhere - but to complete and release work I have again had to leave the Island.

In closing, we note that these disjunctions between the technologies available in different regions will likely close with time; the advancements in computer recording technology may one day make it possible for The Green Mist to write, produce and record an album wholly in the local environment of the far south. Yet, with the construction of Tasmania through Next Stop Antarctica sounded out as a primarily imagined place, and the increasingly portable and transferable notion of local identity, we wonder whether the question will even be relevant. The globe is shrinking, and the end of the world is no longer as far away as it seems.

\section{Bibliography}

Appadurai, A. (1990) 'Disjuncture and difference in the global cultural economy'. In M. Featherstone (ed.) Global Culture: Nationalism, Globalisation and Modernity, London: Sage, pp. 295-310.

Ball, M. (2003) "Pastoral and Gothic in Sculthorpe's Tasmania", TriQuarterly, 116: 115-124.

Bennett, A. (2002) "Music, Media and Urban Mythscapes: A Study of the 'Canterbury Sound"', Media Culture Society, 24: 87-100.

(2004) "Music, Space and Place". In Whitely, S., Bennett, A. \& Hawkins, S. (eds) Music, space and place: popular music and cultural identity, Aldershot: Ashgate.

Casey, E. (1987) Remembering: A Phenomenological Study, Bloomington: Indiana University Press.

Conrad, P. (1988) Down Home: Revisiting Tasmania, London: Chatto \& Windus.

Davidson, J. (1989) “Tasmanian Gothic”, Meanjin, 48(2): 307-324.

Flanagan, M. (1999) “The Hunt for Tasmania”, The Age, 14 Aug. p.4.

Herbert, T. (2002) "The Van Diemenising of Tasmania”, Australian Author, 34(2): 1823.

Keith, M., \& Pile, S. (eds.) (1993) Place and the Politics of Identity, London: Routledge.

Leyshon, A., Matless, D., \& Revill, G. (eds.) (1998) The Place of Music. New York: The Guilford Press. 
Lippard, L. (1997) The Lure of the Local: Senses of Place in a Multicentered society, New York: The New Press.

Lipsitz, G. (1994) Dangerous Crossroads: Popular music, Postmodernism and the Poetics of Place, London: Verso.

Lowenthal, D. (2007) "Islands, Lovers and Others", The Geographical Review, 97(2), 202-229.

Massey, D. (1999) 'Space-time, 'Science' and the relationship between physical geography and human geography", Transactions of the Institute of British Geographers, 24(3): 261-276.

Maxwell, I. (2006) “'Runnin' Amok': An Acoustemology of Place Resounding in Penrith, Western Sydney", in McAuley, G., (ed.) Unstable Ground: Performance and the Politics of Place, Brussels: P.I.E. Peter Lang, 45-61.

McAuley, G. (2006) "Remembering and Forgetting: Place and Performance in the Memory Process", in McAuley, G. (ed) Unstable Ground: performance and the politics of place, Brussels: PIE Peter Lang: 149-176.

Soja, E. (1996) Thirdspace: Journeys to Los Angeles and Other Real-and-Imagined Places, Oxford: Basil Blackwell.

Tumarkin, M. (2001) “'Wishing You Weren't Here...': Thinking about Trauma, Place and the Port Arthur Aassacre", Journal of Australian Studies, 67: 196-208.

Whiteley, S., Bennett, A., \& Hawkins, S. (eds.) (2004) Music, Space and Place: Popular Music and Cultural Identity. Aldershot, UK: Ashgate.

\section{Websites, online reviews and broadcasts}

Green Mist Myspace page - <http://www.myspace.com/themysteriousgreenmist>, first accessed 10 July 2008.

No author, 2007. Green Mist, The. [Online] Bang Records website, accessed 15 July 2008, <http://www.bang-records.net/site/fichabanda.php?id=48>

Cole, B. (2007) “The art of noise refined". Times Online, accessed 10 October 2008, < http://entertainment.timesonline.co.uk/tol/arts_and_entertainment/music/article1 554704.ece>

Mason, S., 2008. "Next Stop Antarctica: Green Mist". Allmusic.com - accessed 16 July 2008, <http://www.allmusic.com/cg/amg.dll?p=amg\&sql=10:dvfpxzwhldde>

Shannon, L., 2008. ABC STATELINE Interview Transcript The Green Mist.

Broadcast: 15/02/2008, Reporter: Lucy Shannon (accessed via email sent from Julien Poulson, 28 July 2008). 